WP 15-31

Mark Holmes

Waikato University, New Zealand

Jesus Otero

University of Rosario, Colombia

Theodore Panagiotidis

University of Macedonia, Greece

The Rimini Centre for Economic Analysis, Italy

\title{
THE EXPECTATIONS HYPOTHESIS AND DECOUPLING OF SHORT- AND LONG-TERM US INTEREST RATES: A PAIRWISE APPROACH
}

Copyright belongs to the author. Small sections of the text, not exceeding three paragraphs, can be used provided proper acknowledgement is given.

The Rimini Centre for Economic Analysis (RCEA) was established in March 2007. RCEA is a private, nonprofit organization dedicated to independent research in Applied and Theoretical Economics and related fields. RCEA organizes seminars and workshops, sponsors a general interest journal The Review of Economic Analysis, and organizes a biennial conference: The Rimini Conference in Economics and Finance (RCEF) . The RCEA has a Canadian branch: The Rimini Centre for Economic Analysis in Canada (RCEACanada). Scientific work contributed by the RCEA Scholars is published in the RCEA Working Papers and Professional Report series.

The views expressed in this paper are those of the authors. No responsibility for them should be attributed to the Rimini Centre for Economic Analysis. 


\title{
The expectations hypothesis and decoupling of short- and long-term US interest rates: a pairwise approach*
}

\author{
Mark J. Holmes \\ Department of Economics \\ Waikato University \\ New Zealand
}

\author{
Jesús Otero \\ Facultad de Economía \\ Universidad del Rosario \\ Colombia
}

\author{
Theodore Panagiotidis \\ Department of Economics \\ University of Macedonia \\ Greece
}

September 2015

\begin{abstract}
The link between short-term policy rates and long-term rates elucidate the potential effectiveness of monetary policy. We examine the US term structure of interest rates using a pairwise econometric approach advocated by Pesaran (2007). Our empirical modelling strategy employs a probabilistic test statistic for the expectations hypothesis of the term structure based on the percentage of unit root rejections among all interest rate differentials. We find support for the expectations hypothesis and provide new insights into the nature of interest rate decoupling which are of value to policymakers. The maturity gap associated with interest rate pairs negatively impacts on the probability of stationarity, and also on the speed of adjustment towards long-run equilibrium. We further show that the speed of adjustment has become more sensitive to the maturity gap over time.
\end{abstract}

JEL Classification: C33; E43.

Keywords: Monetary policy; interest rates; term structure; pair-wise cointegration; speed of adjustment; maturity.

\footnotetext{
*We would like to thank seminar participants at the University of Wakayama and an anonymous referee for helpful comments and suggestions. Any remaining errors are ours. E-mail addresses: holmesmj@waikato.ac.nz; jesus.otero@urosario.edu.co; tpanag@uom.gr.
} 


\section{Introduction}

Monetary policy typically involves the influencing of short-term interest rates by central banks. However, the potential effectiveness of monetary policy actions will depend on the impact that such actions may have on long-term rates. The most influential theory that explains the interaction between interest rates of different maturities is the expectations hypothesis of the term structure (EHTS). According to this, long-term interest rates can be thought of as an average of expected future short-term rates, so that an increase in the long-term rate can be interpreted as implying rising future short-term rates. Because of this, it has long been recognised that the slope of the yield curve constitutes an important source of information for the evolution of future real economic activity. For instance, Estrella and Hardouvelis (1991) not only find that a positive curve slope is associated with future increases in real economic activity, but also that it provides additional predictive power for the latter over other commonly used variables such as leading indicator indices, real short-term interest rates, and past values of rates of inflation and real economic activity. Many macroeconomic models typically employ a single interest rate in representations of the economy despite the presence of a spectrum of differing maturities upon which decision-making is based. If the expectations theory prevails, then central banks can influence long-rates by operating at the short-end of the market. In addition to this, the EHTS is related to the concept of market efficiency insofar as two implications of the EHTS are that the forward rate is an unbiased predictor of future spot rates, and that this predictor cannot be improved by using any currently available information.

Ever since the introduction of the concept of cointegration in the econometrics literature by Engle and Granger (1987), one way of testing the EHTS is based on the idea that interest rates of different maturity maintain a long-term equilibrium relationship, so that the interest rate spread (or differential) does not exhibit a systematic tendency to increase (or decrease) over time such that it reverts to its mean; see, for example, early applications by Engle and Granger (1987), Campbell and Shiller (1987), Stock and Watson (1988), Hall et al. (1992) and Shea (1992). Within this framework, the unit root null hypothesis of a non-stationary interest rate spread is tested against the alternative that the spread is stationary. When interest rates of different maturity are non-stationary, or 
I(1), processes, support for the alternative hypothesis that the interest rate spread is stationary can be viewed as implying that there exists a cointegration relationship between the interest rates, and that the cointegrating vector is equal to $[1,-1]^{\prime}$.

The subsequent large empirical literature on the EHTS has expanded in different directions. Hamilton (1988) and Sola and Driffill (1994) were among the first who examined US treasury bills allowing not only for both short- and long-term interest rates to be non-stationary, but also for changes in regime. The evidence provided by these authors support the EHTS. Within a panel framework, Holmes et al. (2011) provide evidence in favour of stationarity for Asian interest rate spreads. Seo (2003) observes that the presence of transaction costs in financial markets may prevent investors from taking advantage of arbitrage opportunities. Given the latter, the estimation of a threshold vector error correction (VEC) model which allows for nonlinear adjustment to the long-run equilibrium relationship leads this author to provide evidence for nonlinear mean reversion in the term structure of interest rates. Bams and Wolff (2003), in contrast, resoundingly reject the expectations hypothesis for a full data panel of US Treasury securities, using data from 1970:1 to 1994:12 and argue in favour of mean reversion in the US risk premia. More recently, Weber and Wolters (2012) estimate reduced-form bivariate VEC models of the US term structure which allow them to conclude that premia persistence increases with longer-rate maturity. These authors argue that the weight of news is lower for longer horizon investment. Weber and Wolters (2013) document two stylised facts of the US term structure: (i) low contemporaneous cross correlations and (ii) slower adjustment to the underlying long-run equilibrium relationship. Reviewing the literature on the link between the term structure and the macroeconomy, Gürkaynak and Wright (2012) conclude that in the models that explain deviations from the EHTS using time-varying risk premia, inflation uncertainty seems to play the dominant role. Lastly, in a study of Japan, Kagraoka and Moussa (2013) find support for the EHTS during the period of quantitative easing of Japanese monetary policy.

In a further dimension to the EHTS debate, it is notable that during the recent global financial crisis, the US Fed along with other central banks brought down short-run policy interest rates. However, required reductions in longer interest rates were less forthcoming. 
Thornton (2010,2014) and others have noted that the relationship between US Treasury yields and the federal funds rate has in fact changed dramatically since the late 1980s. This is also documented by Cömert (2012) who investigates the relationship between overnight interest rates and the long-term rates in the US from 1983-2007 and finds support for a gradual decoupling between the Fed interest rate and long-term interest rates, even before the recent Global financial crisis.

The purpose of this paper is to employ a pairwise test of the EHTS in a way that not only enables us to assess whether the EHTS holds, but also allows us to incorporate the presence of interest rate decoupling. The presence of cointegration between different interest rate maturities is necessary, but not sufficient evidence in support for long-run EHTS. By imposing a long-run unity restriction linking two interest rate maturities, we then test for a unit root in the spread. Rejecting non-stationarity thereby implies cointegration of the spread based on a unity long-run coefficient. Using a different methodological approach to what has been typically adopted elsewhere in the literature, we combine the use of tools for the analysis of both time-series and cross-section dimensions. Typically, the modelling approach that has been adopted in the existing literature considers the spreads between long-term rates and a given short-term policy rate, where the latter is often taken as the one-period rate. In sharp contrast to this, our pairwise framework allows us to examine the order of integration of all possible spreads over the whole maturity spectrum. In doing so, we provide new insight into long-run EHTS through the application of a test for non-stationarity of interest rate spreads that considers all possible pairings drawn from the maturity spectrum. This includes ten maturities ranging from 3- to 360 month rates. Rather than focus on a range of spreads based on one given short-run rate, it is important to consider all pairings when assessing the stationarity of term structure spreads. For example, interest rates of maturities $m$ and $n$ might be found non-stationary when each measured against a base short-term or policy maturity $p$, but stationary when measured against one another. This would be the case when there is a highly persistent factor that is common to maturities $m$ and $n$, but is not shared by $p$. If the EHTS does hold, then there should be stationarity based on all pairings not just between the policy rate and each other rate in turn. 
In the second stage of our investigation, we turn to a cross section setup where we start by postulating a binary choice (probit) model to determine whether the probability that the spread based on any pair of interest rates is stationary can be explained in terms of the size of the corresponding maturity spread. Next, conditioning on the cases for which stationarity is found, we also estimate a simple cross-section econometric model to explain the speed of adjustment of the stationary interest rate spreads in terms of the corresponding maturity differential. Interestingly, the empirical modelling approach that we adopt is flexible enough to allow us to examine whether the speed of adjustment of interest rate spreads has varied through time. In this respect, a decoupling between shortand long-term rates can be seen in two alternative ways: first, in terms of finding that the probability that an interest rate spread is stationary is smaller when the underlying maturity differential between the rates is larger; second, in terms of a changing speed of adjustment towards a long-run equilibrium as we look along the maturity spectrum. In assessing these linkages involving the maturity differential, the pairwise approach provides us with a sufficient range of pairwise data that facilitates an insight based on formal regression analysis.

The paper is organised as follows. Section 2 presents a brief description of the pair wise approach to test the term structure of interest rates. Section 3 discusses the data. Section 4 presents the results of the empirical analysis and Section 5 offers some concluding remarks.

\section{Econometric methodology: A brief review}

The EHTS of interest rates states that the yield to maturity of an $q$-period bond $r_{q, t}$ will equal an average of the current and future rates on a set of $p$-period short-yields $r_{p, t}$ with $p<q$, plus the term premium reflecting risk and/or liquidity considerations. The relationship can be expressed in the following form

$$
\left(1+r_{q, t}\right)^{q}=\phi_{q, t}^{*} \prod_{k=0}^{q-1}\left(1+E_{t} r_{p, t+k}\right),
$$

where $\phi_{q, t}^{*}$ is a possible non-zero but stationary $q$-period term premium and $E_{t}$ is the 
expectations operator conditional on information up to and including time $t$. The equality in equation (1) is established by the condition of no arbitrage opportunities to investors willing to hold both short-term and long-term bonds. Log-linearising equation (1), we get

$$
r_{q, t}=\phi_{q, t}+\left(\frac{1}{q}\right) \sum_{k=0}^{q-1} E_{t} r_{p, t+k},
$$

where $\phi_{q, t}=\log \left(\phi_{q, t}^{*}\right)$. Equation (2) indicates that the yield of the $q$-period bond and the $p$-period short yields are functionally related. For the subsequent analysis it is convenient to re-express equation (2) as

$$
\left(r_{q, t}-r_{p, t}\right)=\phi_{q, t}+\left(\frac{1}{q}\right) \sum_{k=1}^{q}\left(E_{t} r_{p, t+k-1}-r_{p, t}\right) .
$$

The left hand side of equation (3) represents the spread between the $q$-period (longterm) yield and the $p$-period (short-term) yield as determined by the term premium and investors' expectations of changes in future yields. Assuming that all yields are I(1), whether or not $\left(r_{q, t}-r_{p, t}\right)$ is $\mathrm{I}(0)$ will depend on the time series properties of the right hand side variables, $\phi_{q, t}$ and $1 / q \sum_{k=1}^{q}\left(E_{t} r_{p, t+k-1}-r_{p, t}\right)$, and any relationship between them. Moreover, the spread $\left(r_{q, t}-r_{p, t}\right)$ will be $\mathrm{I}(0)$ if the term premium and investors' expectations of changes in future yields are themselves $\mathrm{I}(0)$. However, $\left(r_{q, t}-r_{p, t}\right)$ might also be $\mathrm{I}(0)$ if the term premium and investors' expectations of changes in future yields are I(1) and cointegrated with a unity vector. On the other hand, $\left(r_{q, t}-r_{p, t}\right)$ will be I(1) if one of term premium and investors' expectations of changes in future yields is $\mathrm{I}(1)$, or if both are I(1) but not cointegrated. Under these scenarios, the EHTS may not hold in the long-run. However, Strohsal and Weber (2014) argue that a non-stationary spread can be reconciled with the long-run EHTS if the spread and term premia are cointegrated. In this respect, a stationary spread could in fact be regarded as sufficient, but not necessary, for the EHTS to hold in the long-run. Despite this caveat, the stationarity or nonstationarity of the term spread is still informative on several fronts that include the potential effectiveness of monetary policy actions.

In the strand of the literature that focuses on the stationarity of the spread, EHTS 
tests based on pairs of maturities across the spectrum reveal significant variation in results often relevant to different parts of the maturity spectrum. For example, Hurn et al. (1995) test the conjecture that the highly competitive nature of the London interbank market will result in longer-term rates determined primarily by expectations of future shortterm rates. They provide results obtained from tests for all possible pairs of interbank maturities and note that the EHTS shows signs of weakness at the short-end of the maturity spectrum. Balcombe (2006) finds evidence for threshold effects in pairs of longer rates, but not in pairs of short rates. Sarno et al. (2007) on the other hand, test the EHTS using U.S. monthly data for bond yields spanning a 1952-2003 sample period with series ranging in maturity from one month to 10 years. While the conventional bivariate procedure provides mixed results, a powerful LM testing procedure suggests rejection of the EHTS throughout the maturity spectrum examined.

In contrast to the above studies, we take a different pairwise approach. Our empirical modelling strategy starts off within a time-series framework by employing the Pesaran (2007) pair wise approach to test for probabilistic convergence among a large number of cross sectional units, which for the purposes of our paper correspond to interest rates at different maturities. Following Pesaran (2007), let $r_{i t}$ be the observed nominal interest rate on a bond with maturity $i$ at time $t$, where $i=1, \ldots, N$ maturities and $t=1, \ldots, T$ time observations. The underlying idea is to study the order of integration of all $N(N-1) / 2$ possible spreads (or differentials) between $i$ and $j$, which we denote as $s_{i j t}=r_{i t}-r_{j t}$, where $i=1, \ldots, N-1$ and $j=i+1, \ldots, N$. For a sample of $N$ interest rates, unit root tests are conducted on all the $N(N-1) / 2$ interest rate spreads. Under the null hypothesis of non-stationarity or rejection of the EHTS, one would normally expect the fraction of interest rate spreads or differentials for which the unit-root hypothesis is rejected to be close to the size of the underlying unit-root tests, denoted as $\alpha$. However, it can be argued that the null of non-stationarity for all interest rate spreads can be rejected if the fraction of rejections exceeds $\alpha$. For this, we consider the application of three unit root tests to the interest rate spread $s_{i j t}$, namely the ADF test of Dickey and Fuller (1979), the $\mathrm{ADF}_{\mathrm{GLS}}$ test of Elliot et al. (1996), and the $\mathrm{ADF}_{\mathrm{MAx}}$ test of Leybourne (1995). Based on these test statistics, let $z_{i j}$ denote an indicator function that is equal 
to one if the corresponding unit-root test is rejected at significance level $\alpha$. Thus, for example, when using the $\mathrm{ADF}_{\mathrm{MAX}}$ test, $z_{i j}^{\mathrm{ADF}_{\mathrm{MAX}}}=1$ if $\operatorname{ADF}_{\mathrm{MAX}}(p)<K_{T, p, \alpha}^{\mathrm{ADF}} \mathrm{MAx}_{\text {, where }}$ $\operatorname{ADF}_{\text {MAX }}(p)$ is the resulting $\operatorname{ADF}_{\text {MAX }}$ test statistic including $p$ lags of the dependent variable, and $K_{T, p, \alpha}^{\mathrm{ADF}_{\mathrm{MAx}}}$ is the corresponding critical value at significance level $\alpha$, based on $T$ observations. The indicator function, which may be constructed in a similar fashion when employing the other two tests, is subsequently used to calculate the percentage of the $N(N-1) / 2$ interest rate differentials for which the unit-root hypothesis is rejected:

$$
\bar{z}=\frac{2}{N(N-1)} \sum_{i=1}^{N-1} \sum_{j=i+1}^{N} z_{i j} .
$$

Panel methods offer the means of addressing low test power attached to univariate methods. In testing for non-stationarity of interest rate differentials across the maturity spectrum, this pair-wise methodology neutralises three disadvantages of existing panel methods such as the panel unit root tests suggested by Maddala and Wu (1999), Levin et al. (2002), Im et al. (2003) and others. First, the joint non-stationary null hypothesis of these panel unit root tests is that all the series have a unit root. However, this hypothesis can be rejected even if the proportion of the interest rate differentials series for which the unit root null is rejected is small. The pair-wise approach directly addresses the question of what proportion of interest rate differentials is stationary. Second, the presence of unobserved common factors complicates the application of the panel unit root tests where cross-section dependence can lead to size distortion. The so-called second generation panel unit root tests (following the terminology in Breitung and Pesaran (2008)) have attempted to allow for possible cross-section dependence through unobserved common factors, but their applications are complicated by the uncertainties surrounding the number of unobserved factors, the nature of the unit root process (whether it is common or country specific), and the fact that longer data spans are required for modelling the cross-section dependence. The pair-wise method is robust to cross-sectional dependence. Third, the use of existing panel unit root tests can necessitate that all series measured against a common base, which is often the short-run policy interest rate. However, the outcome of the non-stationary test can be sensitive to the choice of base interest rate. The pair-wise methodology does not involve what can be a problematic choice of a single 
reference interest rate in the computation of interest rate differentials.

Although typically $\bar{z}$ is in itself the parameter of interest when applying the pairwise approach, see inter alia Pesaran (2007), Pesaran et al. (2009), Yazgan and Yilmazkuday (2011) and Abbott and De Vita (2012), the distinctive feature of our paper is that we rather focus on all the interest rate spreads that turn out to be stationary, as they are characterised by having a constant mean and a constant variance. For these stationary spreads, we calculate the approximated half-life of a shock (measured in months), so that we can subsequently examine whether the speed at which interest rates adjust back to their long-run equilibrium relationship is directly related to the corresponding gap that exists in their associated maturities (where the maturity gap is also measured in months).

\section{Data}

We employ monthly data on Treasury Constant interest rates at 10 different maturities over the period $1993 \mathrm{~m} 10$ to $2015 \mathrm{~m} 4$, which yields a total of 259 time observations for each interest rate series. More specifically, the data correspond to the 3-month, 6-month, 1-year, 2-year, 3-year, 5-year, 7-year, 10-year, 20-year and 30-year constant maturity rates, as retrieved from the Federal Reserve Economic Data (FRED) assembled by the Economic Research Division of the Federal Reserve Bank of St. Louis. The choice of these specific maturities is dictated by the availability of consistent interest rate data with respect to the study period. For this reason, other maturities that are observed over much shorter time periods, such as the 1-month Treasury Constant maturity rate that is available only since $2001 \mathrm{~m} 7$, are excluded from the analysis. The interest rate series under consideration are plotted in Figure 1, and for the purposes of the empirical analysis are measured as percentages. It can be seen that periods of divergence follow periods of convergence in the interest rate levels. Relative convergence can be observed both prior and during the two most recent NBER-dated recessions while divergence tends to follow. 


\section{Empirical analysis}

Our first step is to examine the stationarity properties of all interest rate differentials or spreads. Table 1 presents the point percentage of rejections $\bar{z}$, based on all 45 interest rate differentials, that results from applying the $\mathrm{ADF}, \mathrm{ADF}_{\mathrm{GLS}}$ and $\mathrm{ADF}_{\mathrm{MAx}}$ unit root tests. The tests are performed at the $\alpha=10 \%$ significance level, the optimal lag length is chosen using the Akaike information criterion (AIC), allowing for a maximum of $p_{\max }=4$ lags, and an intercept term is included in the test regressions (so that rejecting the unit root null means that interest rates move together in the long-run, but not that they are the same thereby allowing for a non-zero risk premia). As can be seen from the table, in all cases the point percentage of rejections exceeds the underlying size of the unit root tests, with rejection frequencies of $36 \%, 60 \%$ and $87 \%$ for the ADF, $\mathrm{ADF}_{\mathrm{MAx}}$ and $\mathrm{ADF}_{\mathrm{GLS}}$ tests, respectively. ${ }^{1}$

Although our estimates of the percentages of rejection, $\bar{z}$, reported in Table 1 are well above the empirical size of the unit root tests, offering probabilistic support for the EHTS based on the pairwise approach, they do not constitute the focus of attention in our analysis. Instead, further developing the pairwise approach originally proposed by Pesaran (2007), we examine whether the probability that any interest rate differential or spread is stationary is driven by the maturity gap based on the two interest rate levels. Additionally, we also consider whether the maturity gap influences the speed at which interest rates adjust when they deviate from their long-run equilibrium relationship. In

\footnotetext{
${ }^{1}$ In view of the events that might have affected financial markets, we also applied the Zivot and Andrews (1992) (Lumsdaine and Papell (1997)) unit root test which allows for the presence of one (two) structural break(s) in the intercept, the trend or both at unknown locations. Results not reported here indicate that when one allows for either one or two breaks in the mean of the interest rate spreads, the percentages of rejection of the unit-root null are smaller than in the case when no breaks are allowed, that is $8.9 \%$ at the $10 \%$ significance level. If one instead applies the Perron (1989) test that permits only one break in the constant at a known point in time (for which we chose November 2008, a date that is marked as the start of the quantitative easing programme), then the rejection frequency of the unit-root null is $17.8 \%$ at the $10 \%$ significance level; this percentage still is much smaller compared to those obtained when no breaks are permitted. Although a priori one would expect that allowing for breaks would help reject the null of non-stationarity, it appears that the magnitude of the estimated breaks in the interest rate spreads (if at all present) is not sufficiently large to overturn the conclusion that some of them contain a unit root. Thus, the finding of fewer stationary spreads can be explained by the fact that in the presence of breaks the distribution of the test statistics shifts to the left, and so the required critical values for inference become more negative.
} 
measuring the probability that interest rate spreads are stationary, we use the indicator function $z_{i j}$ described in the previous section. As to the speed of adjustment, for each interest rate spread, $s_{i j t}=r_{i t}-r_{j t}$, that turns out to be stationary, we estimate an approximation of the half-life of a shock based on the estimated autoregressive coefficient that results from estimating an ADF-type regression. At this point, it is worth noting that the resulting half-life between interest rates $i$ and $j$, which we refer to as $h l_{i j}$, is inversely related to the speed of adjustment. The logarithm of the absolute value of the maturity gap (in months) between interest rates $i$ and $j$, denoted by $\ln \left(m g_{i j}\right)$, emerges as a natural candidate for a potential drivers that helps explain $z_{i j}$ and $h l_{i j}$, given that all bonds are issued by the same financial entity; thus, for instance, the maturity gap between the 2-year and 6-month rates is 18 months, and so on. The relationships between $z_{i j}$ and $\ln \left(m g_{i j}\right)$ as well as between $h l_{i j}$ and $\ln \left(m g_{i j}\right)$ can be stated more formally as follows:

$$
\begin{aligned}
& z_{i j}=\alpha_{1}+\alpha_{2} \ln \left(m g_{i j}\right)+\varepsilon_{i j}, \\
& h l_{i j}=\beta_{1}+\beta_{2} \ln \left(m g_{i j}\right)+\epsilon_{i j} .
\end{aligned}
$$

Maximum likelihood estimation of the binary equation (5) using a probit model yields the results reported in Table 2. As can be seen in the table, the estimate of the slope coefficient is negative and statistically significant. ${ }^{2}$ This finding implies that the longer is the maturity gap, then the lower is the probability of a stationary interest rate spread, which would provide support for the view of decoupling between short- and long-term interest rates. The marginal effects are $-38 \%$ and $-18 \%$ for the ADF and $\mathrm{ADF}_{\mathrm{MAx}}$ tests, respectively. This implies that a unit increase in $\ln \left(m g_{i j}\right)$ will cause a decrease in the probability that the outcome corresponding to $z_{i j}=1$ (stationary spread) will occur. ${ }^{3}$ While the earlier results reported in Table 4 provide probabilistic support for the EHTS based on stationary interest rate spreads, those in Table 2 offer refinement of this insofar

\footnotetext{
${ }^{2}$ In the case of the $\mathrm{ADF}_{\mathrm{GLS}}$ test the estimated coefficient is negative but not statistically different from zero. The lack of precision can be explained by the fact that the sample is unbalanced in the sense that it has many more ones (i.e. 87\%) than zeros.

${ }^{3}$ To account for the possibility of nonlinearity in the effect of the maturity gap, the probit models were also estimated including the second power of the maturity gap. However, the estimated coefficient on this additional regressor did not turn out to be statistically different from zero.
} 
as the stationarity of interest spreads is more likely for those interest rate pairs that are closest to each other in maturity.

Regarding the estimation of equation (6), a zero slope would imply that the half-life remains constant across all pairs over the maturity spectrum irrespective of the size of the maturity gap. This scenario would suggest that a change in monetary policy initially affecting the short-term policy rate that then sees short- and long-rates responding over the spectrum at the same speed. In contrast, the estimation of a positive slope would be consistent with the longer rates taking longer to adjust back towards long-run equilibrium. Furthermore, an increasing positive slope over time would be consistent with monetary policy taking longer to influence the longer rates. Indeed, Thornton (2010) argues that the share of variation in the 10-year yield that could be accounted for by the behaviour of the funds rate declined dramatically over the years. Table 3 reports the results of estimating equation (6) by OLS for the cases where the interest rate differentials are stationary, based on the three unit root tests at the $\alpha=10 \%$ level of statistical significance. As can be seen in the lower panel of the table, the coefficients of determination indicate that at least $62 \%$ of the variance in $h l_{i j}$ is accounted for by $\ln \left(m g_{i j}\right)$; moreover, the regression model diagnostic tests are generally satisfactory. Turning to the estimated slope coefficient, it has the expected positive sign and is statistically significant in the three set of results, suggesting that a wider gap in maturity leads to a slower speed of adjustment. Indeed, a unit increase in $\ln \left(m g_{i j}\right)$ leads to a 7.66 (6.44) unit increase in the half-life based on the $\mathrm{ADF}_{\mathrm{GLS}}\left(\mathrm{ADF}_{\mathrm{MAX}}\right)$ unit root test. ${ }^{4}$

As is well known, during the sample period under consideration the US economy has witnessed different shocks as well as the implementation of important policy measures. The former most notably includes the sub-prime crisis. Among the latter, the quantitative easing (QE) policy based on three rounds of QE that have been implemented by the US monetary authorities during the period November 2008 to October 2014 is perhaps the most salient one. Thus, an interesting aspect to look at has to do with the constancy as time progresses of the estimated effect of the maturity gap. ${ }^{5}$ For this, we perform

\footnotetext{
${ }^{4}$ Results not reported here indicate that the inclusion of the second power of the maturity gap as an additional regressor did not yield a statistically significant coefficient.

${ }^{5}$ Kagraoka and Moussa (2013) employ a time varying VAR model for Japan and demonstrate that the term structure of interest rates is supported even during quantitative easing.
} 
a recursive estimation of equation (5) through to $2002 \mathrm{~m} 1$, and then plot the resulting marginal effect (evaluated at the mean value of the regressor) along with its corresponding 95\% confidence interval. Next, we include the following observation so that equation (5) is estimated through to $2002 \mathrm{~m} 2$, and so on until all the observations in the sample are included. The results of the recursive estimation, summarised in Figure 2 for the ADF $\mathrm{MAX}_{\mathrm{X}}$ test, point towards parameter constancy across the study period with perhaps the only notable exception occurring during the years 2008/2009, coinciding with part of the Great Recession peak to trough period defined by the NBER. ${ }^{6}$

At this point, it is also worth examining whether a rolling window produces different results than the recursive approach. To do this it was necessary to increase the length of the moving window to 162 observations (that is, 13.5 years) so that throughout the whole estimation period there were enough (zero and one) observations to estimate equation (5). Thus, the first sub-sample used is $1993 \mathrm{~m} 10$ to $2007 \mathrm{~m} 3$; then $1993 \mathrm{~m} 11$ to $2007 \mathrm{~m} 4$; and so on (care should be exercised when interpreting the results of the rolling estimation though, given that the size of the moving window can be viewed as large relative to the full sample size, i.e. just under two-thirds). The results of the rolling estimation, presented in Figure 3, also support the view that the marginal effect is constant throughout the sample (although there appears to be less precision in the point estimates of the marginal effects starting in 2012, they tend to be contained within previous $95 \%$ confidence intervals).

The stability analysis presented above uses the same set of spreads in all (binary) regressions. Therefore, it seems relevant to analyse the effect of the maturity gap when there is a changing composition in the spreads that are stationary. This can be easily addressed by performing both recursive and rolling estimations of the regression equation (6), and plotting the resulting slope coefficient along with its corresponding 95\% confidence interval. The output of the recursive regressions is summarised in Figure 4 for the case where the $\mathrm{ADF}_{\mathrm{MAx}}$ test is employed to determine which ones of the interest rate differentials are stationary. As can be seen from the figure, the slope coefficients have been increasing in steps through time, supporting the view that a wider gap in maturity leads to an ever slower speed of adjustment involving interest rate pairs. This is

\footnotetext{
${ }^{6}$ The recursive results for the other two unit root tests are qualitatively similar and therefore not reported here for brevity.
} 
consistent with monetary policy becoming less effective over time in terms of influencing long-term interest rates. In turn, the results of the rolling estimation in Figure 5 reveal that (overall) the slope coefficients have been relatively constant as the point estimates fall within previous $95 \%$ confidence intervals.

The recursive and rolling estimates of equation (5) explaining $z_{i j}$ are consistent to the extent that they provide point estimates in the vicinity of -0.2 , with no compelling evidence that the slope coefficient on $\ln \left(m g_{i j}\right)$ is trending upwards or downwards. These two sets of results do differ insofar as the rolling estimates in Figure 3 are characterised by the upper boundary of the $95 \%$ confidence interval exceeding zero from 2012 onwards. Unlike the recursive estimates in Figure 2, this is indicative of an insignificant slope coefficient for the past three years. However, a key factor here could be that the rolling estimates are based on using less data compared with the recursive approach and this is contributing to lower test power.

As to Figures 4 and 5, which respectively report the recursive and rolling estimates of equation (6) that regresses $h l_{i j}$ on $\ln \left(m g_{i j}\right)$, we have consistency insofar as both sets of results point to a positive and significant slope coefficient across the study period (except for 2014 where the rolling window lower confidence boundary falls below zero). Both estimates lend support to the view that an increasing maturity gap will reduce the speed of adjustment. However, there is a key difference insofar as the recursive estimates in Figure 4 point to a slope coefficient that is trending upwards through the study period, i.e. the speed of adjustment is becoming more sensitive to the maturity gap with the implication that monetary policy has become less effective over time. This is not the case for Figure 5 based on a rolling window with no clear trend in the slope coefficient.

In summary, the graphical evidence presented above reinforces the view that the positive trend in Figure 4 is driven by an increasing impact of the maturity gap, and the changing composition in the spreads that are stationary. In terms of our preference between the recursive and rolling estimates, we are inclined to favour the use of the recursive window estimation on the grounds that it utilises the full available time span as we extend the window.

Our theoretical discussion above emphasises that stationary spreads can be supportive 
of the EHTS. While cointegration between interest rates is necessary but not sufficient evidence to support the EHTS, we find that the spreads are in fact stationary according to our application of the Pesaran pairwise testing procedure, whereby stationarity of the spread embodies cointegration between all interest rate pairs with a unity coefficient restriction linking each interest rate. According to our earlier discussion, this is most likely because both the term premia and expectations of future interest rate changes are stationary, or that non-stationary term premia and non-stationary expectations of future interest rate changes are cointegrated with a unity coefficient. Following Strohsal and Weber (2014), one can further argue that the presence of non-stationary spreads (which we find against in our investigation) may not be enough to invalidate the EHTS if the spread and term premia are cointegrated. Weber and Wolters (2012) find that the persistence of risk premia is higher, the larger is the difference in maturity between the considered interest rates. They also find that risk premia persistence stays about the same in both their estimation periods (imposed break at 1988). In contrast, we find that risk premia persistence, dependent on the size of maturity gap, has increased over time. Following Cömert (2012), at first sight our results are supportive of the view that Fed has been gradually losing its control over long-term interest rates. While our analysis is supportive of the EHTS holding in the long-run, it would appear that the period after 2001 has been seen an ongoing process whereby long-term rates are becoming less responsive to changes in monetary policy. Therefore, the experience based on short-run dynamics is one of less integration among interest rates across the maturity spectrum.

\section{Concluding remarks}

For monetary policy to be effective, changes in short-term policy interest rates should impact on long-term ones. Given the importance of the EHTS in modelling interest rate linkages, this study examines the term structure of interest rates via a probabilistic pairwise stationarity approach. We employ US monthly interest rates of ten different maturities from 1993 until 2015. The percentage of rejection of the unit-root null in the interest rate differentials (from $36 \%$ to $87 \%$ ) provides evidence in support of the EHTS holding in the long-run. This suggests that short-run policy changes can have 
the desired effect on long-term rates. However, we also consider decoupling between the short-run policy rate and long-term yields in two alternative ways. First, we test whether the probability that an interest rate spread is stationary is inversely related to the size of maturity spread (in absolute value). An additional log month is associated with a decrease by $38 \%$ in the probability of stationarity. Second, we also focus on decoupling in terms of speed of adjustment. Here, a positive relationship between half-life and the size of maturity spread (in absolute value) emerges. To the extent that the former is assumed to be inversely related to the speed of adjustment, then the larger the size of the maturity gap between interest rates, the slower the speed of adjustment. Although the pairwise unit root testing offers long-run support for the EHTS, we do not see the decoupling of long-term rates from the Fed rate as a manifestation of the EHTS failing. Rather, this is seen as an issue of short-run adjustment of interest rates along the maturity spectrum re-establish long-run equilibrium. 


\section{References}

Abbott, A. and G. De Vita (2012). Pairwise convergence of district-level house prices in London. Urban Studies 49, 721-740.

Balcombe, K. (2006). Bayesian estimation of cointegrating thresholds in the term structure of interest rates. Empirical Economics 31, 277-289.

Bams, D. and C. C. P. Wolff (2003). Risk premia in the term structure of interest rates: a panel data approach. Journal of International Financial Markets, Institutions and Money 13, 211-236.

Breitung, J. and M. H. Pesaran (2008). Unit roots and cointegration in panels. In L. Mátyás and P. Sevestre (Eds.), The Econometrics of Panel Data, pp. 279-322. Berlin: Springer-Verlag.

Campbell, J. Y. and R. J. Shiller (1987). Cointegration and tests of present value models. Journal of Political Economy 95, 1062-1088.

Cheung, Y. and K. S. Lai (1995a). Lag order and critical values of the augmented DickeyFuller test. Journal of Business and Economic Statistics 13, 277-280.

Cheung, Y.-W. and K. S. Lai (1995b). Lag order and critical values of a modified Dickey and Fuller test. Oxford Bulletin of Economics and Statistics 57, 411-419.

Cömert, H. (2012). Decoupling between the federal funds rate and long-term interest rates: Decreasing effectiveness of monetary policy in the U.S. Working Papers wp295, Political Economy Research Institute, University of Massachusetts at Amherst.

Dickey, D. A. and W. A. Fuller (1979). Distribution of the estimators for autoregressive time series with a unit root. Journal of the American Statistical Association 74, 427431.

Elliot, G., T. J. Rothenberg, and J. H. Stock (1996). Efficient tests for an autoregressive unit root. Econometrica 64, 813-836.

Engle, R. F. and C. W. J. Granger (1987). Cointegration and error correction: Representation, estimation and testing. Econometrica 55, 251-276.

Estrella, A. and G. A. Hardouvelis (1991). The term structure as a predictor of real economic activity. Journal of Finance 46, 555-576.

Gürkaynak, R. S. and J. H. Wright (2012). Macroeconomics and the term structure. Journal of Economic Literature 50, 331-367.

Hall, A. D., H. M. Anderson, and C. W. J. Granger (1992). A cointegration analysis of treasury bill yields. The Review of Economics and Statistics 74, 116-126. 
Hamilton, J. D. (1988). Rational-expectations econometric analysis of changes in regime: An investigation of the term structure of interest rates. Journal of Economic Dynamics and Control 12, 385-423.

Holmes, M. J., J. Otero, and T. Panagiotidis (2011). The term structure of interest rates, the expectations hypothesis and international financial integration: Evidence from Asian economies. International Review of Economics and Finance 20, 679-689.

Hurn, A. S., T. Moody, and V. A. Muscatelli (1995). The term structure of interest rates in the London interbank market. Oxford Economic Papers 47, 419-436.

Im, K., M. H. Pesaran, and Y. Shin (2003). Testing for unit roots in heterogeneous panels. Journal of Econometrics 115, 53-74.

Kagraoka, Y. and Z. Moussa (2013). Quantitative easing, credibility and the time-varying dynamics of the term structure of interest rate in Japan. Journal of International Financial Markets, Institutions and Money 25, 181-201.

Levin, A., C.-F. Lin, and C.-S. J. Chu (2002). Unit root tests in panel data: Asymptotic and finite-sample properties. Journal of Econometrics 108, 1-24.

Leybourne, S. (1995). Testing for unit roots using forward and reverse Dickey-Fuller regressions. Oxford Bulletin of Economics and Statistics 57, 559-571.

Lumsdaine, R. L. and D. Papell (1997). Multiple trend breaks and the unit root hypothesis. Review of Economics and Statistics 79, 212-218.

Maddala, G. S. and S. Wu (1999). A comparative study of unit root tests with panel data and a new simple test. Oxford Bulletin of Economics and Statistics 61, 631-652.

Otero, J. and J. Smith (2012). Response surface models for the Leybourne unit root tests and lag order dependence. Computational Statistics 27, 473-486.

Perron, P. (1989). The great crash, the oil price shock and the unit root hypothesis. Econometrica 5\%, 1361-1401.

Pesaran, M. H. (2007). A pair-wise approach to testing for output and growth convergence. Journal of Econometrics 138, 312-355.

Pesaran, M. H., R. P. Smith, T. Yamagata, and L. Hvozdyk (2009). Pairwise tests of purchasing power parity. Econometric Reviews 28, 495-521.

Sarno, L., D. L. Thornton, and G. Valente (2007). The empirical failure of the expectations hypothesis of the term structure of bond yields. Journal of Financial and Quantitative Analysis 42, 81-100. 
Seo, B. (2003). Nonlinear mean reversion in the term structure of interest rates. Journal of Economic Dynamics and Control 27, 2243-2265.

Shea, G. S. (1992). Benchmarking the expectations hypothesis of the interest-rate term structure: An analysis of cointegration vectors. Journal of Business 83 Economic Statistics 10, 347-366.

Sola, M. and J. Driffill (1994). Testing the term structure of interest rates using a stationary vector autoregression with regime switching. Journal of Economic Dynamics and Control 18, 601-628.

Stock, J. M. and M. W. Watson (1988). Testing for common trends. Journal of the American Statistical Association 83, 1097-1107.

Strohsal, T. and E. Weber (2014). Mean-variance cointegration and the expectations hypothesis. Quantitative Finance 14, 1983-1997.

Thornton, D. L. (2010). The unusual behavior of the federal funds and 10-year treasury rates: a conundrum or Goodhart's law? Working Papers 2007-039, Federal Reserve Bank of St. Louis.

Thornton, D. L. (2014). Monetary policy: Why money matters (and interest rates don't). Journal of Macroeconomics 40, 202-213.

Weber, E. and J. Wolters (2012). The US term structure and central bank policy. Applied Economics Letters 19, 41-45.

Weber, E. and J. Wolters (2013). Risk and policy shocks on the us term structure. Scottish Journal of Political Economy 60, 101-119.

Yazgan, M. E. and H. Yilmazkuday (2011). Price-level convergence: New evidence from U.S. cities. Economics Letters 110, 76-78.

Zivot, E. and D. W. K. Andrews (1992). Further evidence on the great crash, the oil price shock, and the unit root hypothesis. Journal of Business and Economic Statistics 10, 251-270. 
Table 1: Point fraction of rejections

\begin{tabular}{lc}
\hline Unit root test & $\bar{z}$ \\
\hline & \\
$\mathrm{ADF}$ & $35.6 \%$ \\
$\mathrm{ADF}_{\mathrm{GLS}}$ & $86.7 \%$ \\
$\mathrm{ADF}_{\mathrm{MAX}}$ & $60.0 \%$ \\
\hline
\end{tabular}

Notes: The unit root tests are performed at the 10\% significance level. The critical value for the $\mathrm{ADF}, \mathrm{ADF}_{\mathrm{GLS}}$ and $\mathrm{ADF}_{\mathrm{MAx}}$ are based on response surfaces estimated by Cheung and Lai (1995a), Cheung and Lai (1995b) and Otero and Smith (2012), respectively. 
Table 2: Probit models for the determinants that interest rate differentials are stationary

\begin{tabular}{|c|c|c|c|c|c|c|}
\hline \multirow[b]{2}{*}{ Variable } & \multicolumn{2}{|c|}{$\mathrm{ADF}$} & \multicolumn{2}{|c|}{$\mathrm{ADF}_{\mathrm{GLS}}$} & \multicolumn{2}{|c|}{$\mathrm{ADF}_{\mathrm{MAX}}$} \\
\hline & Coefficient & (s.e.) & Coefficient & (s.e.) & Coefficient & (s.e.) \\
\hline Intercept & 4.244 & $(1.268)$ & 2.200 & (1.104) & 2.355 & $(0.888)$ \\
\hline $\ln \left(m g_{i j}\right)$ & -1.122 & $(0.308)$ & -0.244 & $(0.235)$ & -0.478 & $(0.193)$ \\
\hline Marginal effect & -0.383 & $(0.103)$ & -0.050 & $(0.046)$ & -0.182 & $(0.072)$ \\
\hline Obs. & 45 & & 45 & & 45 & \\
\hline McFadden $R^{2}$ & 0.418 & & 0.034 & & 0.117 & \\
\hline LR-statistic & 24.440 & {$[0.000]$} & 1.190 & {$[0.276]$} & 7.100 & {$[0.008]$} \\
\hline
\end{tabular}

Notes: Numbers in [•] are the probability values of the diagnostic test statistics. Marginal effects were evaluated at the mean value of the regressor, and their standard errors were computed using the Delta-method. 
Table 3: Determinants of the half-life of interest rate differentials $\left(h l_{i j}\right)$

\begin{tabular}{|c|c|c|c|c|c|c|}
\hline \multirow[b]{2}{*}{ Variable } & \multicolumn{2}{|c|}{$\mathrm{ADF}$} & \multicolumn{2}{|c|}{$\mathrm{ADF}_{\mathrm{GLS}}$} & \multicolumn{2}{|c|}{$\mathrm{ADF}_{\mathrm{MAX}}$} \\
\hline & Coefficient & (s.e.) & Coefficient & (s.e.) & Coefficient & (s.e.) \\
\hline Intercept & -0.817 & $(2.660)$ & -8.233 & $(4.308)$ & -6.990 & $(3.104)$ \\
\hline $\ln \left(m g_{i j}\right)$ & 3.912 & $(0.790)$ & 7.657 & $(0.982)$ & 6.444 & $(0.756)$ \\
\hline Obs. & 16 & & 39 & & 27 & \\
\hline Mean dependent variable & 11.769 & & 24.007 & & 18.247 & \\
\hline$R^{2}$ & 0.636 & & 0.622 & & 0.744 & \\
\hline Hetero & 0.390 & {$[0.685]$} & 2.540 & {$[0.093]$} & 1.074 & {$[0.357]$} \\
\hline Normality & 1.918 & {$[0.383]$} & 2.806 & {$[0.246]$} & 1.333 & {$[0.513]$} \\
\hline
\end{tabular}

Notes: We include only the stationary pairs based on the $\mathrm{ADF}, \mathrm{ADF}_{\mathrm{GLS}}$ and $\mathrm{ADF}_{\mathrm{MAX}}$ unit-root tests at the $10 \%$ significance level. Hetero is the F-version of the White Heteroskedasticity test of unknown form, based on the auxiliary regression of the squared residuals against a constant, the original regressors and their squares. Normality is the $\chi^{2}$ version of the Jarque-Bera test. Numbers in $[\bullet]$ are the probability values of the diagnostic test statistics. 
Figure 1: Treasury constant interest rates at selected maturities (in months)

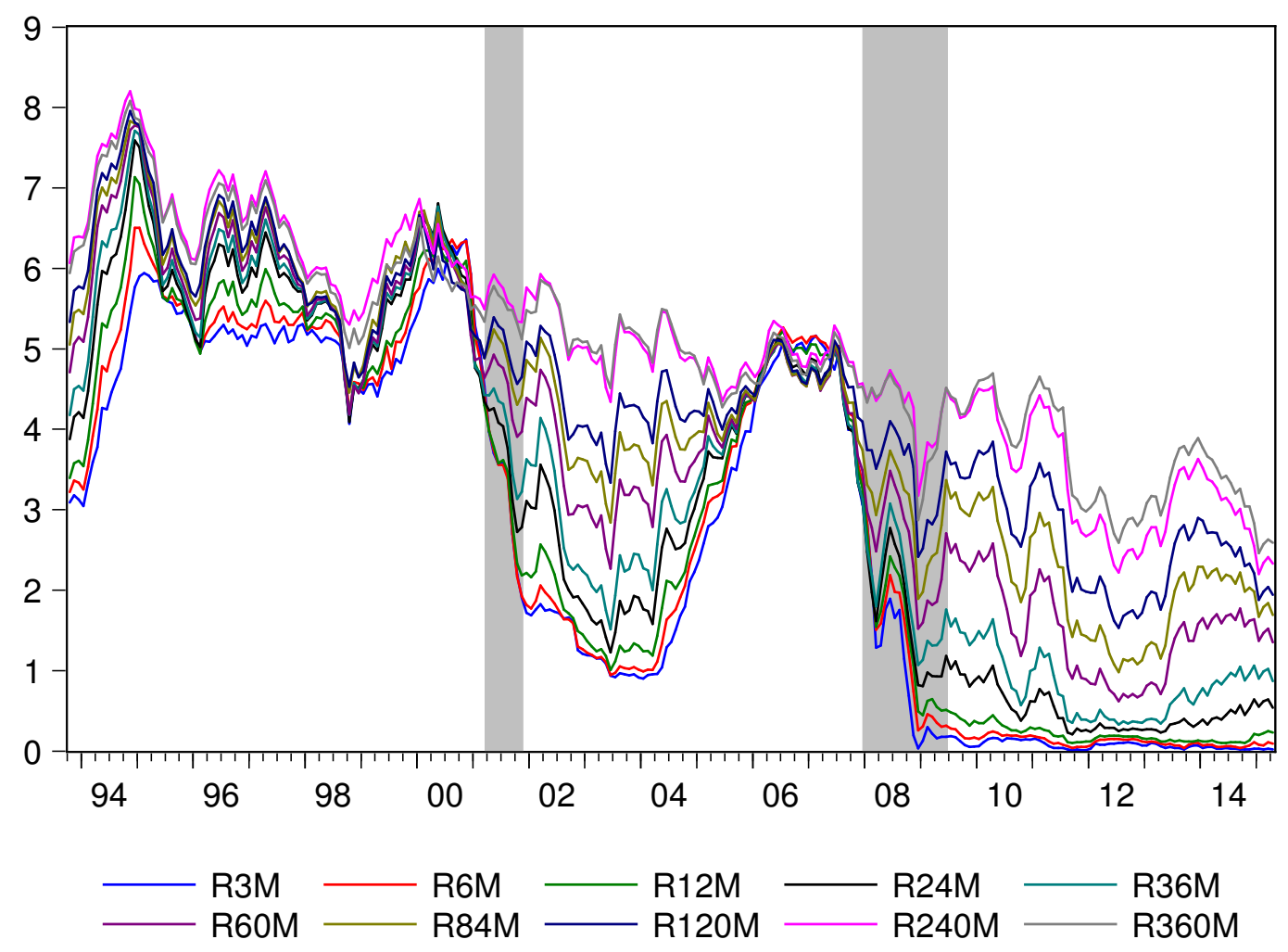

Note: Source: The data series have been downloaded from the Federal Reserve Economic Data (FRED) assembled by the Economic Research Division of the Federal Reserve Bank of St. Louis. The shadowed areas in the figure indicate the National Bureau of Economic Research peak to trough periods. 
Figure 2: Recursive estimation of the probit model for the stationary differentials based on $\mathrm{ADF}_{\text {MAX }}$ test

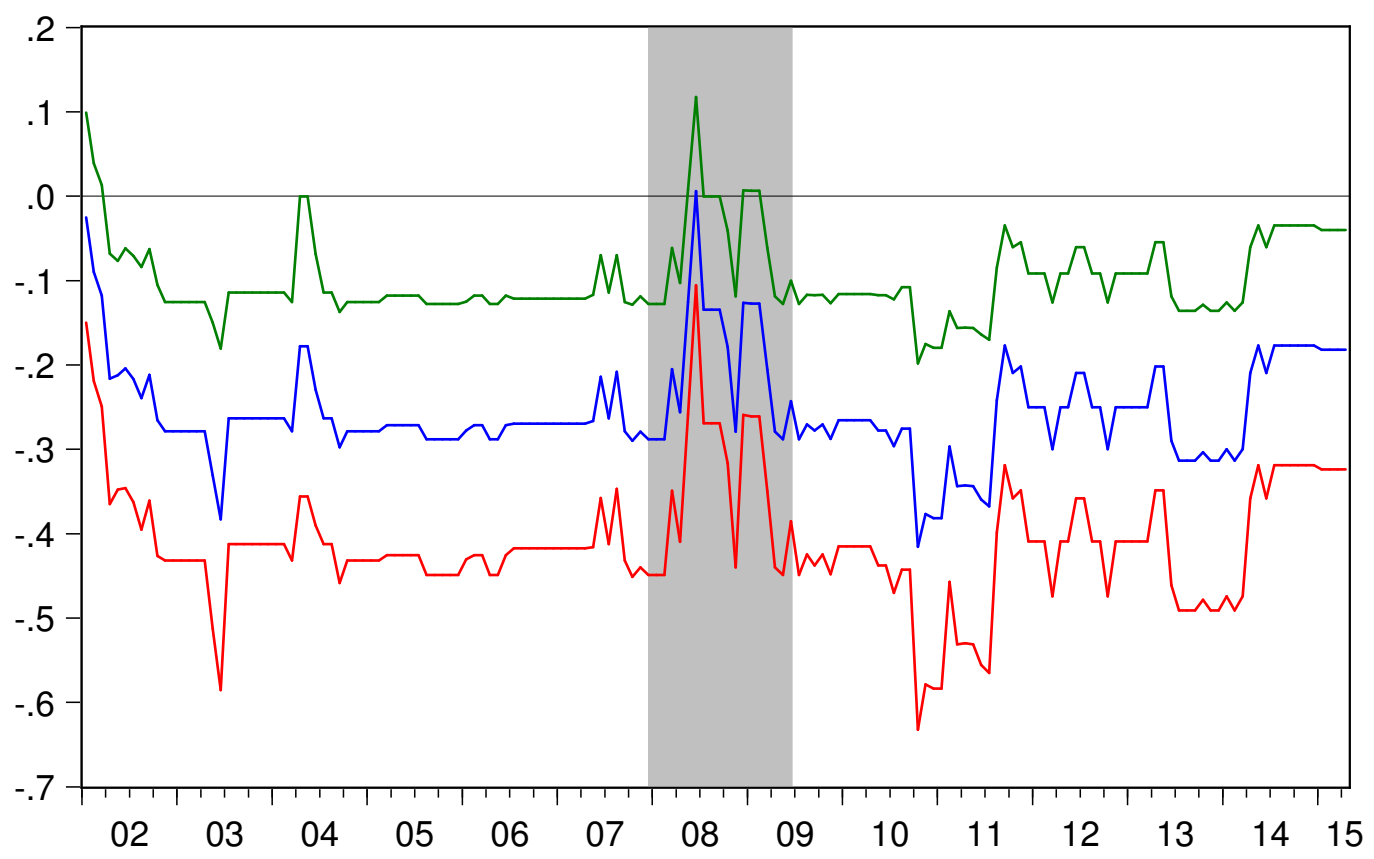

Note: The figure plots the marginal effect and $95 \%$ confidence interval when equation (5) is estimated recursively (marginal effects are evaluated at the mean value of the regressor). The first data point is the marginal effect when estimation is performed until $2002 \mathrm{~m} 1$. The last data point is the marginal effect when all available observations are used in the estimation process. The shadowed area in the figures indicates the National Bureau of Economic Research peak to trough period. 
Figure 3: Rolling estimation of the probit model for the stationary differentials based on $\mathrm{ADF}_{\text {MAX }}$ test

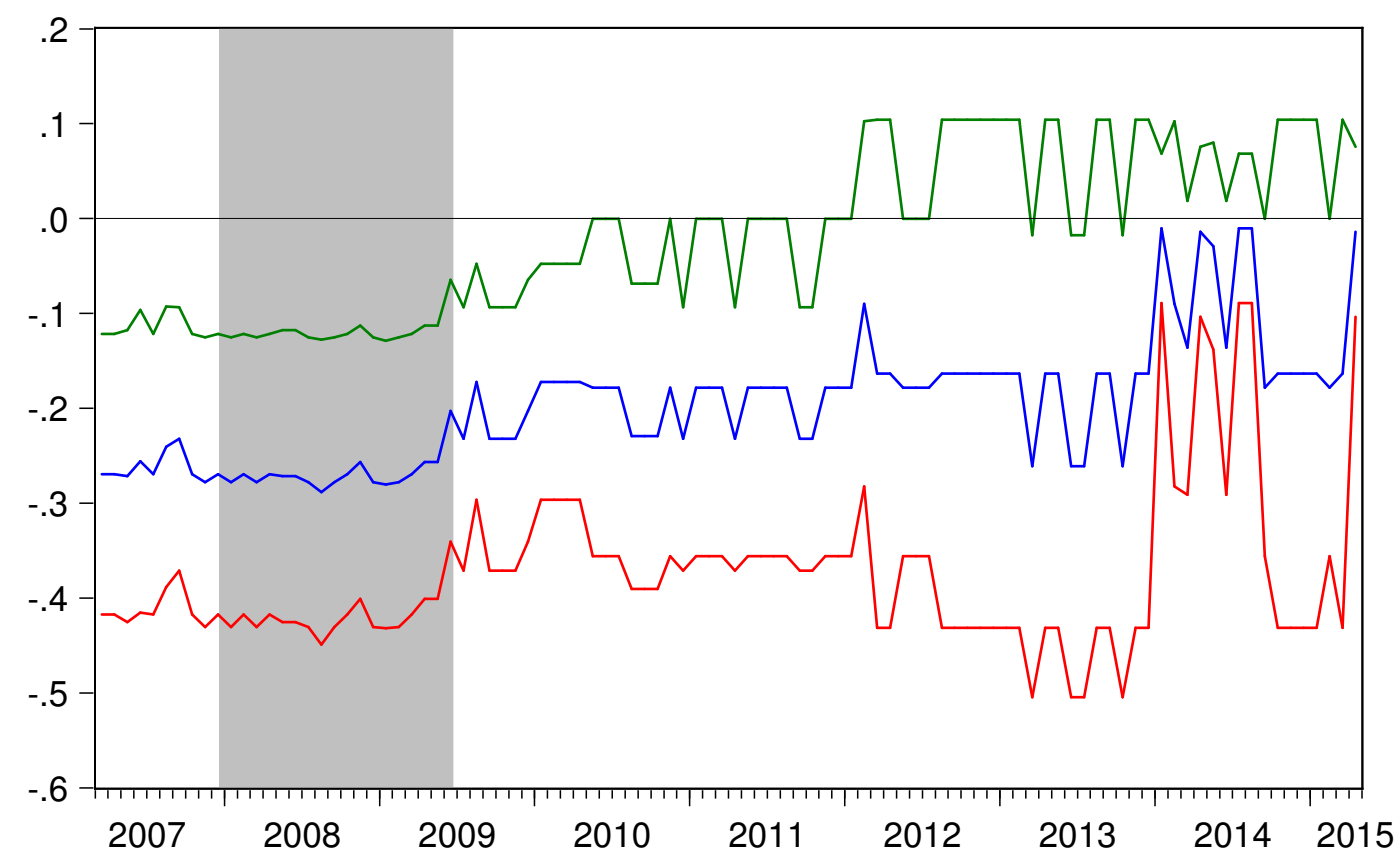

Note: The figure plots the marginal effect and $95 \%$ confidence interval when equation (5) is estimated in a rolling fashion (marginal effects are evaluated at the mean value of the regressor). The first data point is the marginal effect when estimation is performed until $2008 \mathrm{~m} 9$. The last data point is the marginal effect when estimation is performed over the sub-sample $2000 \mathrm{~m} 5$ to $2015 \mathrm{~m} 4$. The shadowed area in the figures indicates the National Bureau of Economic Research peak to trough period. 
Figure 4: Recursive estimation of the half-life of stationary differentials based on ADF $_{\text {MAX }}$ test

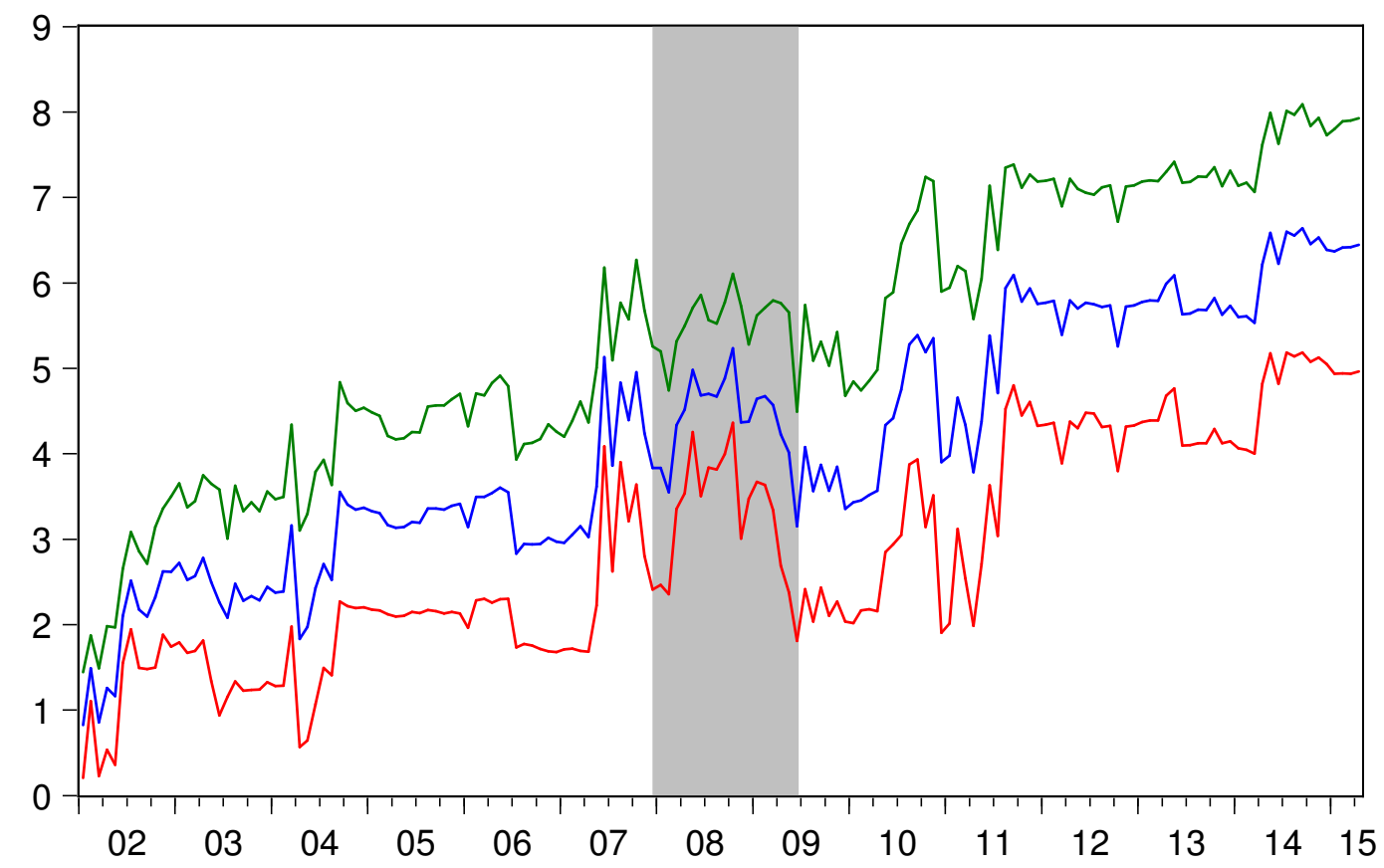

Note: The figure plots the slope coefficient (and 95\% confidence interval) when equation (6) is estimated recursively. The first data point is the coefficient obtained when estimation is performed until $2002 \mathrm{~m} 1$. The last data point is the coefficient obtained when all available observations are used in the estimation process. The shadowed area in the figures indicates the National Bureau of Economic Research peak to trough period. 
Figure 5: Rolling estimation of the half-life of stationary differentials based on $\mathrm{ADF}_{\mathrm{MAX}}$ test

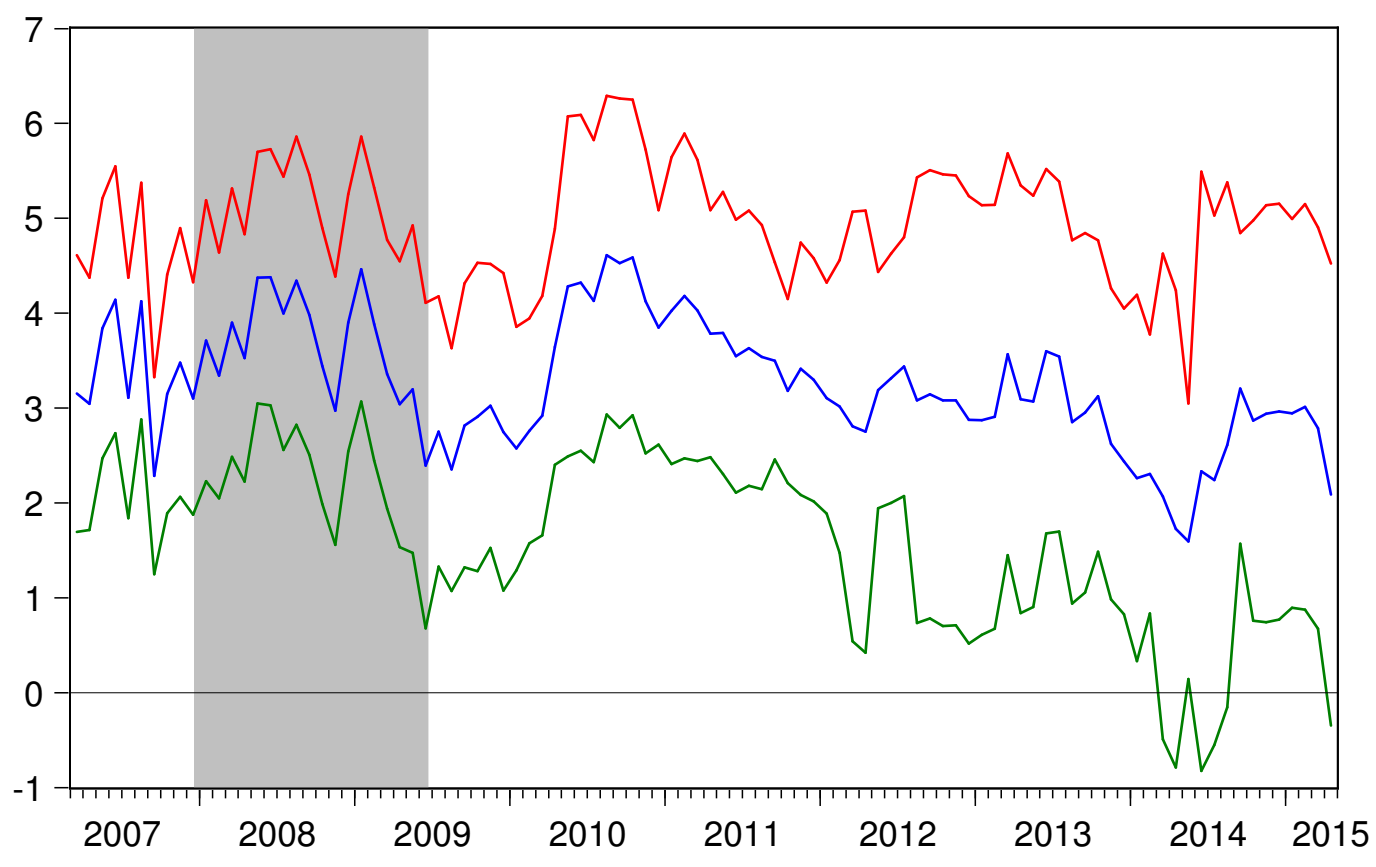

Note: The figure plots the slope coefficient (and 95\% confidence interval) when equation (6) is estimated in a rolling fashion. The first data point is the coefficient obtained when estimation is performed until $2008 \mathrm{~m} 9$. The last data point is the coefficient when estimation is performed over the sub-sample $2000 \mathrm{~m} 5$ to $2015 \mathrm{~m} 4$. The shadowed area in the figures indicates the National Bureau of Economic Research peak to trough period. 